\title{
PENSANDO AS ELEIÇÕES E OS SENTIDOS DO LULISMO
}

\author{
João Kamradt ${ }^{1}$ \\ Josnei Di Carlo ${ }^{2}$
}

Entrevista com o prof. Dr. André Singer ${ }^{3}$

\begin{abstract}
Nascido em 1958, André Singer graduou-se em Ciências Sociais em 1980 e em Jornalismo em 1986 pela Universidade de São Paulo (USP). Obteve o título de mestre em 1993, doutor em 1998 e livre docente em 2011 na mesma instituição de ensino superior. Por causa de sua dupla formação, tanto exerce o jornalismo quanto à docência. Foi secretário de redação do jornal Folha de S. Paulo no biênio 1987-1988 e desde 1990 é professor. Sua militância no Partido dos Trabalhadores (PT) o levou a tornar-se portavoz da presidência da República no primeiro mandado de Luís Inácio Lula da Silva e secretário da imprensa da Presidência da República de 2005 a 2007. Após sua experiência governamental, procurou compreender o fenômeno do lulismo no artigo Raízes Sociais e Ideológicas do Lulismo, publicado em novembro de 2009 na revista Novos Estudos, do Centro Brasileiro de Análise e Planejamento (CEBRAP). Em 2012, sistematizou suas análises no livro Os Sentidos do Lulismo, tornando-se um marco no pensamento social brasileiro.

De maio a junho de 2014, o Programa de Pós-Graduação em Sociologia Política (PPGSP) da Universidade Federal de Santa Catarina (UFSC) ofertou a disciplina Problemas do Brasil Contemporâneo, no qual procurou mapear as interpretações sobre o Brasil produzidas a partir da Constituição de 1988. Entre as obras abordadas, estava $O s$
\end{abstract}

\footnotetext{
${ }^{1}$ Mestrando do curso de Sociologia Política da UFSC. Formado em Comunicação Social com ênfase em Jornalismo. Email para contato: joaokamradt@gmail.com

${ }^{2}$ Doutorando no curso de Sociologia Política da UFSC. É mestre em Ciência Polícia, pela UFSCar. Bacharel em Ciências Sociais, pela UEL. Email para contato: josneidicarlo@ hotmail.com.br ${ }^{3}$ A entrevista foi realizada no dia 30 de junho de 2014, antes de um debate realizado na UFSC sobre o livro Os Sentidos do Lulismo.
}

Em Tese, Florianópolis, v. 10, n. 2, jul./dez., 2013. ISSN: 1806-5023 
Sentidos do Lulismo. Encerrando a disciplina ministrada por Jacques Mick, André Singer refletiu sobre sua obra e a debateu com Yan Carreirão, no auditório do Centro de Filosofia e Ciências Humanas, em 30 de junho.

Antes da conferência, João Kamradt e Josnei Di Carlo, integrantes da equipe editorial da revista Em Tese, encontraram-se com André Singer para a realização desta entrevista. Nela, o entrevistado trata de questões conceituais referentes ao lulismo, do sistema eleitoral, do PT, do Governo de Dilma Rousseff e da Eleições de 2014.

Revista Em Tese - Uma das críticas feitas a sua obra, é de que o lulismo, como conceito, não existiria. A argumentação seria de que não há uma corrente ideológica que leve a um lulismo. Da mesma forma, outros estudos apontam na direção de que houve nos últimos anos foi um peemedebismo, com o PT avançando em alianças pragmáticas ao invés de manter a ideologia do passado. Nisso, quero questionar se o senhor não enxerga que esse poderia ser apontamentos complementares: um que aponta da existência de um lulismo convergente com o que é chamado de peemedebismo?

André Singer - Acho que pensar o lulismo como uma ideologia, de fato, apresenta problemas que eu não enfrentei no livro. Acho que o lulismo deve ser entendido melhor como uma invenção política, como uma criação política que aconteceu nos dois mandatos do ex-presidente Lula, que eu chamei de lulismo porque acho, que de alguma maneira, a figura dele, enquanto liderança política encarna essa invenção política que ocorreu naquele período. Essa invenção, basicamente é a ideia de você fazer transformações no Brasil que tem, possivelmente, ao longo do tempo um caráter estrutural, mas que são feitas sem confrontos com o capital. Essa, digamos, é aquilo que está no núcleo do lulismo. Se isso vai se transformar em uma ideologia só o tempo irá dizer. Eu não apresento isso como uma hipótese que tenha um desdobramento ideológico. Pode tanto vir a ter como não, dependendo do próprio processo político. Com relação à questão do peemedebismo, acho que são em parte, como vocês formularam na pergunta, hipóteses complementares. São ângulos diferentes para enxergar o período. Quando eu falo que o PT, de alguma maneira, mudou sua 
orientação em direção ao lulismo, estou chamando atenção para o fato de que o PT deixou de ser um partido de ruptura e passou a ser um partido mais amigável em relação ao capital. Essa transformação não fica muito presente quando se fala em peemedebismo. Quando se fala em peemedebismo está se olhando mais para a questão de determinadas práticas políticas do que para o problema das classes socais. Acredito que o que diferencia esses dois ângulos, que seriam a ideia de lulismo e a ideia do peemedebismo, é o problema da centralidade que a luta de classes teria ou não.

Revista Em Tese - No posfácio de Os Sentidos do Lulismo, o professor destaca a importância do 18 Brumáriopara sua análise sobre o lulismo. O bonapartismo é uma categoria forte no pensamento político brasileiro. Foi usado tanto para se pensar a Revolução de 1930 quanto o Golpe de 1964. Ao professor usar o bonapartismo não denota uma continuidade do lulismo em relação aos dois eventos históricos citados? Há continuidade, apesar da diferença fundamental de que o lulismo é produto de um realinhamento eleitoral e não de uma revolução e de um golpe?

André Singer - Uso bastante o 18 Brumário, mas não a categoria de bonapartismo. O 18 Brumário é um texto inspirador sob diversos pontos de vista. Eu fui inspirado pela ideia da base de classes dos fenômenos políticos. Na conjuntura francesa que o Marx analisou e, no caso nosso, eu penso que o ponto comum é a existência de uma base social desorganizada. No caso da França, os pequenos proprietários do campo e aqui no Brasil, o que eu tenho chamado de subproletariado. Então, acho que é mais esse aspecto que importa na leitura do 18 Brumário para mim. O bonapartismo é um tipo de formação política que, em geral, está associada a intervenções militares. E, no caso do lulismo, não há nada que se pareça com isso e nem que tenha qualquer relação com isso. Os militares estão completamente fora da política brasileira e espero que isso continue assim. Acredito que irá continuar. De modo que não há nenhuma relação entre o lulismo e o bonapartismo desse ponto de vista. É preciso tomar bastante cuidado com as categorias porque senão a gente pode introduzir no debate falsas questões. Em função disso, prefiro não usar a categoria de bonapartismo. 
Revista Em Tese - O professor abre Os Sentidos do Lulismo notando que Lula é marcado pela contradição. Como candidato, a aura das lutas operárias da década de 1970 e 1980 ilumina Lula. Ao assumir a Presidência, Lula toma medidas neoliberais. Ao fim de seu governo, Lula reaviva o desenvolvimentismo. Poderíamos fazer essa mesma analogia com Dilma. Como candidata, a aura do desenvolvimentismo ilumina Dilma. Ao assumir a Presidência, Dilma toma medidas neoliberais. Ambos os processos demostram que o neoliberalismo não é um instrumento eleitoral, mas é um instrumento de governo? O neoliberalismo não sustenta o realinhamento eleitoral, mas sustenta a governança? Portanto, uma das raízes da contradição do lulismo não deriva do sistema eleitoral?

André Singer - Acredito que as contradições do lulismo precisam ser apanhadas em uma outra chave. Não acredito que tenha sido implementada propriamente uma política neoliberal. Aliás, eu diria até o contrário. O lulismo foi uma interrupção da política neoliberal no Brasil. O que aconteceu foi que aspectos da política neoliberal, importantes, mas não a política neoliberal como um todo, foram incorporados dentro do lulismo. Repito: aspectos importantes, mas apenas aspectos. Por quê? Porque esses aspectos se juntaram com propostas e programas que vão no sentido oposto, como o aumento do salário mínimo, como a geração de empregos, para citar duas das mais importantes políticas que são o contrário do neoliberalismo. O que é surpreendente no lulismo, o que faz com que a gente precise olhar para o fenômeno com bastante cuidado é que ele não apresenta as características esperadas, mais fáceis de aprender porque seriam, digamos, mais previsíveis. O que aconteceu foi a construção de uma política nova e diferente, que traz dentro de si aspectos neoliberais e outros aspectos que são anti-neoliberais. Portanto, o resultado é algo inesperado.

Revista Em Tese - Nas manifestações para o ano passado, entre as inúmeras críticas feitas, uma recorrente era das pessoas que se diziam "contra os partidos políticos". No seu livro, o senhor identifica um lulismo e não um petismo. Esse recorrente personalismo da política aliado a uma insatisfação da população fará as instituições 


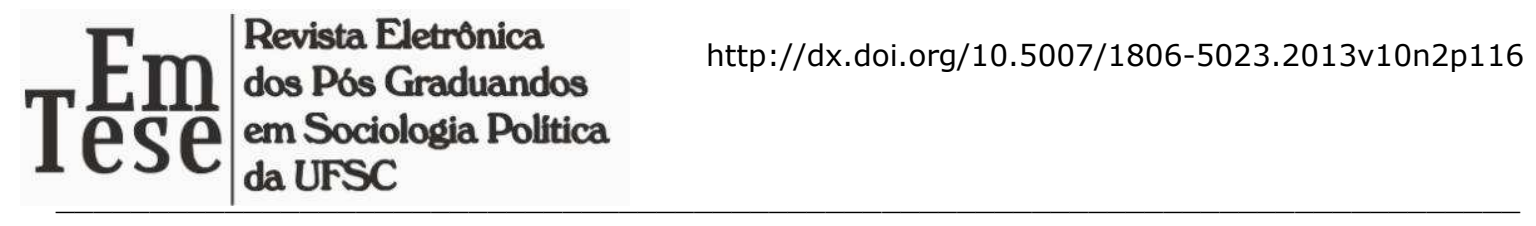

mudarem? Quais os novos caminhos que os partidos precisam trilhar para se manterem em sintonia com a população?

André Singer - Hoje, no mundo e não só no Brasil, existe uma crise generalizada dos partidos políticos. Há um esvaziamento acentuado dos partidos políticos em todas as democracias, um fenômeno que não está inteiramente compreendido. Mas é grave e representa um enorme desafio para o futuro das democracias. Talvez esse seja o principal desafio contemporâneo, uma vez que a democracia foi um enorme avanço social e político e, portanto, algo a ser preservado e aprofundado, evitando-se todos os tipos de riscos de retrocesso. Assim, o problema dos partidos políticos não é apenas brasileiro, mas ele também é brasileiro. Ou seja, o Brasil está dentro de um conjunto de democracias nas quais os partidos políticos estão sendo fortemente contestados. Como fazer para superar essa questão? Eu diria: aumentando a participação social e popular. De alguma maneira, se a sociedade aumentar sua taxa de participação, é possível que haja uma reapropriação dos partidos pela sociedade, mesmo que isso signifique inventar novos partidos políticos. Não estou dizendo que, necessariamente, todos os partidos que existem serão reapropriados pela sociedade, mas o sistema partidário, sem o qual não se inventou forma da democracia funcionar, precisaria ser revitalizado pela entrada em cena de novos atores sociais. Isso, em certa medida, está acontecendo, com o movimento do Occupy Wall Street, com o movimento dos indignados e com as manifestações de junho de 2013 no Brasil e nos seus desdobramentos. Por que digo em certa medida? Porque as manifestações de junho em si, acabaram sendo acontecimentos muito contraditórios. Você tem um movimento que começa na esquerda e acaba em uma espécie de confluência de todas as ideologias, de uma maneira que até confunde um pouco o seu sentido. Daí, que eu acho, da maneira como ocorreu, não vai voltar a ocorrer. Porque, ao final de julho de 2013, o sentido político e ideológico de cada movimento se separou e irá caminhar separado. Mas, voltando à questão dos partidos, penso que o caminho para uma revitalização dos partidos está dado pelo aumento do teor de participação social. E, evidentemente, os partidos terão que se abrir para esse tipo de movimento. É isso que permitiria que eles ganhassem nova vida. No caso brasileiro, possivelmente isso passasse pela reforma política que, por exemplo,

Em Tese, Florianópolis, v. 10, n. 2, jul./dez., 2013. ISSN: 1806-5023 


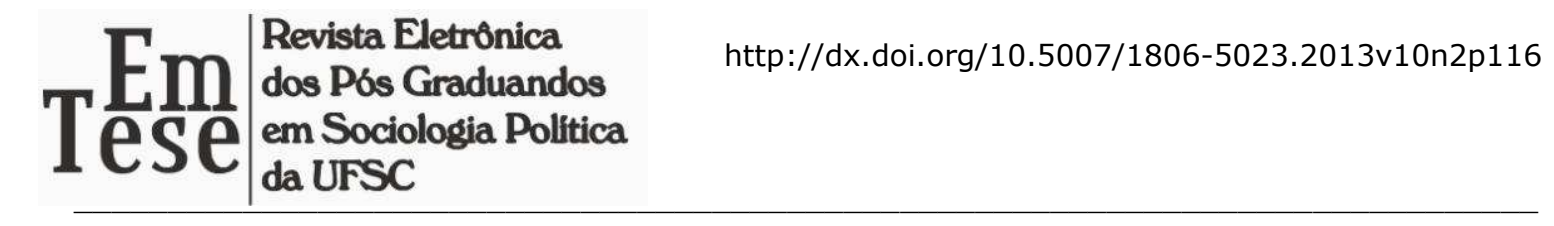

diminuísse drasticamente o poder do dinheiro sobre as campanhas políticas, fazendo com que o cidadão comum tivesse mais chance de participação.

Revista Em Tese - O professor identifica três fases econômicas no Governo Lula: 2003-2005 (marcada pelo Bolsa Família), 2006-2008 (pelo aumento do salário mínimo), 2009-2010 (pelo Programa Minha Casa Minha Vida), quando o Estado passa a ter um comando preponderante sobre a economia. O sucesso da última fase se traduziu na vitória de Dilma em 2010. A economia ainda está na terceira fase? As concessões do Governo Dilma não marcariam uma passagem para outra fase?

André Singer - Creio que o governo Dilma tentou dar prosseguimento ao que eu chamo de terceira fase fazendo uma redução importante dos juros, a partir de meados de 2011 e depois, incidindo sobre a taxa de câmbio, juntamente com a continuidade dos investimentos públicos de infraestrutura de um modo que até o segundo semestre de 2012, ou seja, a primeira etapa do mandato da presidente Dilma, houve uma continuidade, até um aprofundamento da terceira fase, que vocês descreveram muito bem na pergunta. Do segundo semestre de 2012, sobretudo a partir de 2013, com a volta da elevação dos juros, essa política se interrompe e ela é marcada por um conjunto de concessões ao capital e entre essas concessões, a própria reintrodução das privatizações, que o governo chama de concessões, mas eu acho que são, na realidade, formas de privatização, que caracterizam uma interrupção da terceira fase, colocando um ponto de interrogação sobre o futuro do lulismo. Nós não sabemos para onde vai o lulismo diante de uma situação internacional desfavorável, com uma prolongada estagnação econômica na Europa e nos EUA, resultando em uma queda no ritmo de crescimento no mundo todo e, também, no Brasil. Os economistas tendem a achar que o Brasil precisa ter um crescimento de $4 \%$ a $5 \%$ para que as políticas do lulismo possam ter pleno êxito. De modo que existe hoje esse grande ponto de interrogação que é saber como a economia brasileira pode voltar a crescer nesse ritmo que permitiria dar continuidade ao projeto.

Revista Em Tese - O professor fala das duas almas do PT, do Sion (radical) e do Anhembi (moderada). A primeira cisão interna ocorreu nas fileiras do radicalismo petista. 2010, com Marina Silva, e 2014, com Eduardo Campos, não indicam que uma 
segunda cisão está se consolidando no PT, agora nas fileiras dos setores moderados do partido e da base aliada?

André Singer - Eu diria que não. Tanto uma quanto a outra, ou seja, tanto a cisão da Marina Silva em relação ao PT quanto a do Eduardo Campos (PSB) em relação a base governista, e não em relação ao PT, não incidem sobre o que eu chamaria de alma do PT. O Eduardo Campos nunca foi do PT, então não haveria de se supor que ele mexesse com o equilíbrio interno do partido. Já a Marina Silva foi uma liderança importante do partido e acho que a saída dela tem uma consequência para a questão ambiental e para um aspecto ideológico importante que até agora não foi muito bem analisado, que é a questão do pós-materialismo. Ainda assim, reconhecendo que a Marina Silva teve uma importância dentro do PT, não creio que ela tenha representado uma alteração da interna do PT, tal como eu como foi a emergência da segunda alma em 2002.

Revista Em Tese - Em quatro meses teremos às eleições. Há muito tempo não víamos um cenário tão incerto como o de agora que se apresenta com as três candidaturas a postos. Em 2006 e 2010, o senhor identificou o movimento do lulismo, com o voto da classe pobre indo para o PT, enquanto o da classe média, que historicamente votava com os petistas, indo para o PSDB. Nessa eleição, em 2014, a tendência do voto no lulismo deve se manter?

André Singer - Acredito que sim. Claro que em função da diminuição do ritmo do crescimento econômico há uma insatisfação com relação a presidente Dilma, que hoje, pela força do cargo que ocupa, é a principal representante do lulismo, uma vez que o presidente Lula não está no governo. E, essa insatisfação começa a atingir as bases populares, sobretudo nos grandes centros urbanos. Estamos vivendo uma situação nova, que até agora o lulismo não viveu. A previsão que posso fazer, falando no final de junho de 2014, sabendo que as nossas ciências humanas não são boas de previsão, é que o voto popular, sobretudo no Nordeste, vai se manter. Não temos condição ainda de saber até que ponto essas bases poderão ser erodidas nos grandes centros urbanos. A grande questão é que as oposições, nas figuras de Aécio Neves (PSDB) e Eduardo Campos (PSB) até agora, não apresentam alternativas aceitáveis pelas camadas populares. Existe 
uma insatisfação que começa a bater também nos segmentos mais populares, mas não existe ainda uma alternativa que supere o lulismo. De tal maneira que tenderá a manter esse voto. Fazer previsões é muito arriscado, de modo que apenas estou fazendo apenas umas considerações sobre o quadro como ele pode ser visto em junho de 2014.

Revista Em Tese - Conforme o professor, o realinhamento eleitoral a sustentar o lulismo se consolidou em 2006. Nas eleições de 2014, todos os candidatos se voltarão para o bloco de eleitores do realinhamento eleitoral?

André Singer - Tendo em vista que houve um realinhamento, claro que a principal meta das oposições é desfazê-lo. Porque enquanto ele permanecer é muito difícil vencer os candidatos do lulismo, dado o fato de que, pela desigualdade brasileira, o eleitorado popular é muito maior que o eleitorado de classe média. Nesse sentido, sem dúvida, esse é o desafio principal para a oposição. Até aqui, o que eu vejo, é as oposições tendo êxito na classe média, mas não vejo, como disse na resposta anterior, uma reversão do quadro entre os setores populares.

Revista Em Tese - O varguismo tinha uma oposição bem demarcada na UDN. O lulismo tem uma oposição tão bem demarcada como a varguista? A agenda lulista não foi incorporada pela oposição?

André Singer - Acho que nesse sentido as demarcações são bem parecidas. Os tempos mudaram, as questões são outras, as classes sociais são outras, o próprio capitalismo é outro, a gente não pode perder de vista esse conjunto de transformações, mas o grau de polarização e o tipo de polarização que havia entre o PTB e UDN não é muito diferente ao que existe hoje entre o PT e o PSDB, no qual você tem uma alternativa popular e uma outra alternativa fortemente amparada na classe média, o que resulta nessa polaridade entre ricos e pobres, que continua se mantendo. 